\title{
Promising in vitro performances of nickel-free nitrogen containing stainless steels for orthopaedic applications
}

\author{
MOHD TALHA, C K BEHERA and O P SINHA* \\ Centre of Advanced Study, Department of Metallurgical Engineering, Indian Institute of Technology \\ (Banaras Hindu University), Varanasi 221 005, India
}

MS received 10 June 2013; revised 29 October 2013

\begin{abstract}
The aim of the present work was to study the in vitro corrosion resistance in Hank's solution and biocompatibility of indigenized low-cost Ni-free nitrogen containing austenitic stainless steels (HNSs) and to compare with conventionally used 316 L and 316LVM. The electrochemical behaviour was assessed using electrochemical impedance spectroscopy, potentiostatic polarization and scanning electron microscopy. The MTT assay [3-(4,5-dimethythiazol 2-yl)-2,5-diphenyltetrazolium bromide] was performed using Dalton's lymphoma cell line for cytotoxicity evaluation and cell adhesion test. The resistance of surface film was raised by increasing nitrogen content in stainless steel (SS). The corrosion current density was decreased with increase in nitrogen content and corrosion potentials for HNS were observed to be more positive. Shallower and smaller pits were associated with HNS, indicating that nitrogen suppresses the pit formation. The HNS had higher cell proliferation and cell growth and it increases by increasing the nitrogen content. The surface wettability of the alloys was also investigated by water contact-angle measurements. The value of contact angles was found to decrease with increase in nitrogen content. This indicates that the hydrophilic character increases with increasing nitrogen content, which is further attributed to enhance the surface free energy that would be conducive to cell adhesion, which in turn increases the cell proliferation.
\end{abstract}

Keywords. HNS; EIS; 316LVM; implants.

\section{Introduction}

Austenitic stainless steels (e.g. AISI 316L), cobalt-based alloys, commercially pure titanium (CP-Ti) and Ti-6Al$4 \mathrm{~V}$ alloy are most widely used metallic biomaterials. However, there is growing interest in Ti and its alloys, particularly as dental and orthopaedic implants because of their relatively lower modulus of elasticity, superior biocompatibility and higher corrosion resistance (Woodman et al 1984). The 316L grade of stainless steel (SS), however, is still the widely used material for internal fixation devices like fracture plates, screws, hip nail and artificial joints because of their good mechanical properties, corrosion resistance, easy processing, acceptable biocompatibility and very low cost as compared with those of other metallic implant materials (Disegi and Eschbach 2000; Schmidt et al 2001). The resistance of SS to corrosion is due to the presence of a thin oxide passive film on its surface (Milosev and Strehblow 2000; Olsson and Landolt 2003). But the passive film is highly susceptible to localized corrosion such as pitting, crevice corrosion

\footnotetext{
*Author for correspondence (opsinha.met@itbhu.ac.in)
}

and stress corrosion cracking when used as implants (Thomann and Uggowitzer 2000; Kuroda et al 2002).

It has been reported that SS corrodes in body environment and releases iron, chromium and nickel (Sumita 1997). As we are aware that 316L contains $12-15 \%$ of nickel, which can be toxic to the human body if released. There are sufficient evidences that high levels of nickel ions in tissues can cause genotoxic and mutagenic activity or in contact with the skin can cause most widespread contact allergy (Vahter et al 2002; Takazawa et al 2003) and cancer (IARC 1999; Bal et al 2000). The problems caused by nickel-containing alloys have led to development of nickelfree austenitic SSs. To maintain the austenitic microstructure of the alloy, nickel reduction is balanced by the addition of austenite phase stabilizer, i.e. nitrogen and manganese. These nickel-free high nitrogen austenitic stainless steels (HNSs) are a potential alternative material owing to its better mechanical properties, very good corrosion resistance and excellent biocompatibility (Menzel et al 1996; Tschiptschin et al 1999; Thomann and Uggowitzer 2000). The addition of nitrogen has been reported to considerably increase the passive film stability and resistance towards pitting corrosion, crevice corrosion, intergranular corrosion and stress corrosion cracking in some media (Newman et al 1984; Clayton1986; Newman and Shahrabi 1987; Mudali et al 1994, 1996; Baba et al 2002). 
Addition of nitrogen produces beneficial effects for the resistance to pitting corrosion by increasing the pitting potential, suppressing the metastable pits (Palit et al 1993; Ohno et al 1998; Pattersson 1999) and facilitating the re-passivation rate immediately after the breakdown of the passive film (Lee 2006). Nitrogen-containing steels also exhibit superior biocompatibility than nickelcontaining alloys. Yamamoto et al (2004) and Ma et al (2012) have evaluated the cytocompatibility of nickelfree austenitic SS and observed that nickel-free SS had higher cell growth than nickel-containing steel. Wan et al (2010) and Ren et al (2011) have studied the effect of nitrogen content on blood compatibility of HNS including platelet adhesion and kinetic clotting time. They observed that as the nitrogen content in the alloy is increased, the amount of adherent platelets is further decreased and the initial clotting time becomes longer. In vitro studies on biocompatibility using primary osteoblasts and in vivo studies after bone implantation in the sheep tibia of steel, P558, indicate that P558 was much biocompatible with promising future as an implant material (Fini et al 2003, 2004).

In the present study, in vitro corrosion behaviour and biocompatibility of in-house prepared nickel-free austenitic SS for application as biomaterials was evaluated. Usually, steels which are used for biomedical applications contain low carbon $(\leq 0 \cdot 03 \%)$. But, some newly developed high nitrogen medical grade SSs also contain carbon. For example, P558 alloy contains about 0.20 wt\% carbon and F2581 contains $0 \cdot 15-0.25$ wt $\%$ carbon (ASTM F 2581-07; Thomann and Uggowitzer 2000). To analyse the effect of carbon with nitrogen, one alloy which contains high nitrogen $(0.34 \mathrm{wt} \%)$ as well as carbon $(0.48 \mathrm{wt} \%)$ and two more alloys having low carbon $(\leq 0.08 \mathrm{wt} \%)$, but high nitrogen $(0.43 \mathrm{wt} \% \mathrm{~N}$ and $0.52 \mathrm{wt} \%$ $\mathrm{N})$ were selected for the present study. The results were compared with conventional high-quality nickel grades (316L and 316LVM) being used in these applications. The techniques used for the characterization of the corrosion resistance were electrochemical impedance spectroscopy (EIS) and potentiostatic polarization. Finally, SEM was used to understand the surface morphology of the alloys after corrosion studies. The MTT assay was performed using DL cell line for cytotoxicity evaluation and cell adhesion test. The surface wettability was also investigated by water contact-angle measurement.

\section{Experimental}

\subsection{Materials}

Three austenitic SSs (316 $\mathrm{MnN}_{1}, 316 \mathrm{MnN}_{2}$ and $316 \mathrm{MnN}_{3}$ ) with different nitrogen contents $(0.34 \mathrm{wt} \% \mathrm{~N}, 0.43 \mathrm{wt} \% \mathrm{~N}$ and $0.52 \mathrm{wt} \% \mathrm{~N}$ ) were prepared in the form of ingots, respectively, by melting iron and ferro-alloys (Cr, Mo, $\mathrm{Mn}$, high nitrogen ferro-chrome, etc.) in appropriate proportions to meet the aimed composition of alloy in an induction furnace. These ingots were solutionized at $1050-1070{ }^{\circ} \mathrm{C}$ to avoid segregation. Then, specimens of $80 \times 15 \times 6 \mathrm{~mm}$ were cut from ingot, hot-rolled at $1050{ }^{\circ} \mathrm{C}$ to reduce the thickness by $50-80 \%$, solution treated at $1050-1070{ }^{\circ} \mathrm{C}$ for $30 \mathrm{~min}$, and, then, water quenched. The 316L and 316LVM SSs were obtained from Mishra Dhatu Nigam Ltd. (MIDHANI), Hyderabad, India. These steel were received in hot-rolled and annealed condition and used for the study as such. The chemical compositions of all five austenitic SSs are shown in table 1 . Coupons of $10 \times 10 \mathrm{~mm}$ size were cut from them and polished successively with emery papers of 600800-1000-1200 grades. Specimens were washed with deionized water, followed by acetone, and dried in air.

\subsection{Electrochemical corrosion}

2.2a Electrodes and electrolyte: Each coupon was soldered onto one surface with an insulated copper wire and carefully coated with epoxy resin, leaving the other surface (which had a surface area of $1 \mathrm{~cm}^{2}$ ) exposed for corrosion studies. The exposed metal surface was then mirror polished on revolving selvyt cloth using alumina of $0.3 \mu$, washed with deionized water followed by acetone and dried just before test. These specimens were used as working electrodes for the electrochemical corrosion studies. The electrochemical experiments were carried out in Hank's solution of $\mathrm{pH}$ value of $7 \cdot 4 \pm 0 \cdot 2$, prepared in deionized water (Gurappa 2002). The chemicals used to prepare the solution were of analytical reagent grade and were used without further purification. The solution of about $200 \mathrm{~mL}$ was used for electrochemical tests and the temperature was maintained at $37^{\circ} \mathrm{C}(98.4 \mathrm{~F})$, which is equivalent to human body temperature (Gurappa and Kumar 2000).

Table 1. Composition of stainless steels (wt\%).

\begin{tabular}{|c|c|c|c|c|c|c|c|c|c|c|}
\hline Sample & $\mathrm{C}$ & $\mathrm{Cr}$ & Mn & $\mathrm{Ni}$ & $\mathrm{Si}$ & Mo & S & $\mathrm{P}$ & $\mathrm{N}$ & $\mathrm{Fe}$ \\
\hline $316 \mathrm{~L}$ & $0 \cdot 021$ & $17 \cdot 19$ & $1 \cdot 56$ & $14 \cdot 0$ & 0.71 & $2 \cdot 77$ & 0.004 & $0 \cdot 015$ & 0.060 & Bal. \\
\hline 316LVM & $0 \cdot 021$ & $17 \cdot 24$ & $1 \cdot 68$ & $14 \cdot 42$ & $0 \cdot 24$ & $2 \cdot 83$ & 0.004 & 0.007 & $0 \cdot 07$ & Bal. \\
\hline $316 \mathrm{MnN}_{1}$ & $0 \cdot 48$ & $19 \cdot 32$ & $12 \cdot 77$ & 0.05 & $0 \cdot 26$ & $3 \cdot 32$ & 0.006 & 0.009 & $0 \cdot 34$ & Bal. \\
\hline $316 \mathrm{MnN}_{2}$ & $0 \cdot 08$ & $19 \cdot 11$ & $11 \cdot 85$ & $0 \cdot 08$ & $0 \cdot 25$ & $3 \cdot 02$ & 0.004 & $0 \cdot 010$ & $0 \cdot 43$ & Bal. \\
\hline $316 \mathrm{MnN}_{3}$ & $0 \cdot 017$ & $18 \cdot 28$ & 11.92 & 0.04 & 0.07 & $3 \cdot 24$ & 0.003 & 0.008 & $0 \cdot 52$ & Bal. \\
\hline
\end{tabular}


2.2b Apparatus and procedures: The electrochemical experiments were carried out using a standard threeelectrode cell assembly, in which platinum wire and dip-type saturated calomel electrodes (luggin capillary) were used as counter and reference electrodes, respectively. The studies were performed using CHI760C electrochemical workstation with DC software for corrosion. The working electrode was held in the test solution at $37^{\circ} \mathrm{C}$ for $5 \mathrm{~h}$, prior to each experiment, to attain stabilized open-circuit potential $\left(E_{\mathrm{OC}}\right)$. The temperature of the cell was controlled thermostatically using a thermostat (JULABO Labotechnic Gmbh, West Germany) at the experimental temperature. The potential of working electrode was measured against saturated calomel electrode (SCE). EIS measurements were carried out in a frequency range from $10^{5}$ to $1 \mathrm{~Hz}$ under potentiostatic conditions, with an amplitude of $5 \mathrm{mV}$ peak to peak, using a.c. signal at $E_{\mathrm{OC}}$. ZSimpwin software was used for simulating the experimental EIS data.

Potentiostatic polarization curves were obtained by changing the electrode potential automatically from $-1 \cdot 2$ to $2 \mathrm{~V}$ vs $E_{\mathrm{OC}}$ at a scan rate of $0.01 \mathrm{~V} \mathrm{~s}^{-1}$. A constant distance of approximately 1-2 $\mathrm{mm}$ between the tip of luggin capillary and working electrode surface was maintained throughout the experiment. The current was passed through the cell at different pre-determined values through the counter electrode and the equilibrium potential between the working and reference electrodes was measured. Potential values at a given current were found to be generally constant within $1 \mathrm{~min}$. The corrosion potential $\left(E_{\text {corr }}\right)$, corrosion current density $\left(I_{\text {corr }}\right)$ as well as other parameters were automatically extracted from the polarization curves by the tafel extrapolation. All the measurements were repeated at least three times and a fresh solution was used for the new test. Finally, scanning electron microscopy (SEM), FEI Quanta 200FEG, was used to understand the surface morphology of SSs, after corrosion studies.

\subsection{Contact angle measurement}

Contact angles were measured with Kruss F-100 tensiometer for thin strip $\left(20 \times 10 \times 1 \mathrm{~mm}^{3}\right)$ of SS samples at room temperature in water medium. Three different experiments were done for each kind of sample and the measured results were averaged.

\subsection{Cytocompatibility evaluation}

Fetal bovine serum (FBS) was obtained from Invitrogen, Grand Island, NY, USA. Con-A, PMA and MTT were purchased from Sigma Chemical Company, Bangalore, India. RPMI-1640 culture medium was obtained from HiMedia, Mumbai, India. All other chemicals stated otherwise were obtained either from Super Religare Laboratory (SRL), Mumbai, India, or HiMedia, Mumbai, India. A spontaneously occurring $\mathrm{T}$ cell lymphoma commonly called as Dalton's lymphoma (DL) were harvested from DL-bearing mice after 18 days of post-DL cells transplantation, when yield is maximum, and subjected for experimental setting.

In vitro biocompatibility of austenitic SS samples was evaluated using DL cell line. The cells were maintained and cultured in RPMI-1640 medium supplemented with $10 \%$ FBS, antibiotic and antifungal (100 units per $\mathrm{mL}$ penicillin, $100 \mu$ g per $\mathrm{mL}$ streptomycin and $0.025 \mu \mathrm{g}$ per $\mathrm{mL}$ amphotericin), at $37^{\circ} \mathrm{C}$ in a humidified chamber in $5 \% \mathrm{CO}_{2}$ atmosphere. For experimental setting and/or for subculture, cells were harvested, washed and seeded at a density of $0.5 \times 10^{6}$ cells per well in a standard proliferation assay. The coupons of SSs were sterilized by autoclaving at $121^{\circ} \mathrm{C}$ for $20 \mathrm{~min}$ and immersed in RPMI1640 medium containing $10 \%$ FBS at $37{ }^{\circ} \mathrm{C}$ in $5 \% \mathrm{CO}_{2}$ in separately located bottom of 24-well plate for 48 and $72 \mathrm{~h}$. Thereafter, the extract was used to carry out the cytotoxicity/viability assays. Proliferation/cytotoxicity assay was performed in a 96-well microtiter plate seeded with $0.5 \times 10^{6}$ cells per wells and $10 \mu \mathrm{L}$ of MTT [3-(4,5dimethythiazol 2-yl)-2,5-diphenyltetrazolium bromide] was added to freshly prepared PBS $(5 \mathrm{mg} / \mathrm{mL})$ and incubated for 6-12 h, thereafter cells were centrifuged for $5 \mathrm{~min}$ at $100 \mathrm{~g}$ at $4{ }^{\circ} \mathrm{C}$. Supernatant was then carefully discarded without disturbing the dark-blue formazan crystals and $200 \mu \mathrm{L}$ of DMSO was added to each well to dissolve the formazan crystals and absorbance was taken at $595 \mathrm{~nm}$. All experiments were carried out at least three times and three samples of each type were used for each time point. Mean and standard deviation of the optical density (OD) values obtained for three replicates of each sample were calculated. The viability of the cells can be calculated by the following equation

$$
\begin{aligned}
\text { Cell viability }(\%)= & \mathrm{OD}_{595}(\text { sample }) / \mathrm{OD}_{595} \text { (control) } \\
& \times 100 .
\end{aligned}
$$

For cell attachment test, the SS coupons were separately located into the bottom of 24-well microplate/35 mm petri dish. DL cells at the density of $1 \times 10^{6}$ cells per $\mathrm{mL}$ were seeded onto the coupons and cultured in $5 \% \mathrm{CO}_{2}$ at $37{ }^{\circ} \mathrm{C}$ in a humidified chamber for 1,3 and 5 days, respectively, and thereafter cell suspension was discarded and the samples were washed three times in cold PBS to remove any unattached cell. Adherent cell populations were then fixed in $2.5 \%$ of glutaraldehyde solution for $45 \mathrm{~min}$ and dehydrated using a graded ethanol series (50, 60, 70, 80, 90 and $100 \%$ of ethanol) for 10 min each. Samples were dried in air and observed under SEM.

\section{Results and discussion}

\subsection{Electrochemical corrosion}

3.1a Electrochemical impedance spectroscopy (EIS): To investigate the relative stability of the passive films 

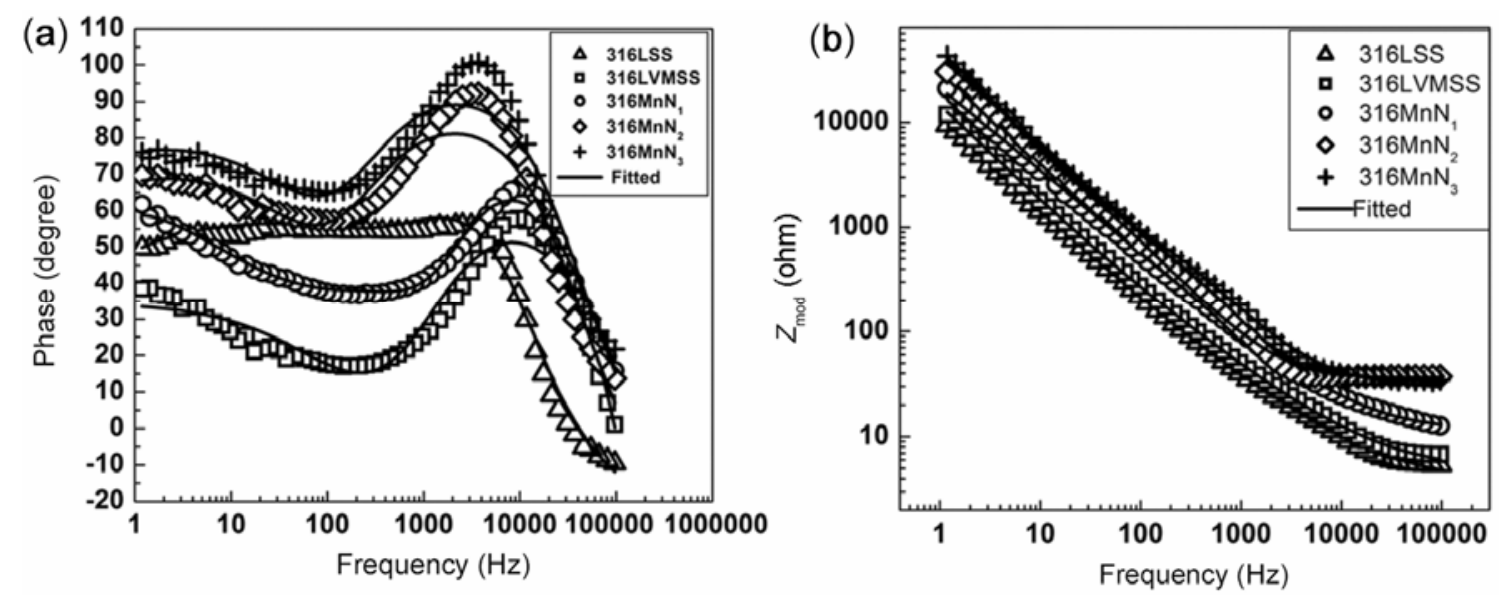

Figure 1. Bode plots of different SSs in Hank's solution at $37^{\circ} \mathrm{C}$ : (a) Bode phase plots and (b) Bode modulus plots.

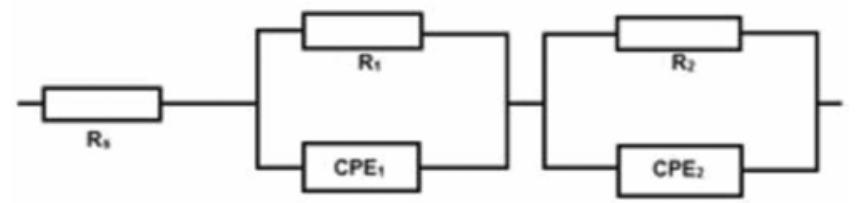

Figure 2. Equivalent electric circuits for quantitative evaluation of EIS spectra.

formed on the surface of different SSs, impedance spectra were recorded at the passive potential after passive film generation. Figure 1(a and b) show Bode (phase and modulus) diagrams of the recorded EIS spectra of SS samples at $37^{\circ} \mathrm{C}$ in Hank's solution. All spectra were analysed in terms of their equivalent electric circuits (EECs) presented in figure 2. In fitting procedure, when only one time constant was used in modelling of the EIS spectrum, a large discrepancy between the experimental and modelled data was observed. However, when the EEC presented in figure 2 was used, the agreement between the experimental (shown by point symbols) and modelled (shown by solid line) data was excellent. Because the impedance data of a solid/electrolyte interface often reveal a frequency dispersion that is attributed to a 'capacitive dispersion', the capacitance is expressed in terms of the constant-phase element (CPE) (Jorcin et al 2006). The impedance of the CPE is given by

$$
Z_{\mathrm{CPE}}=\frac{1}{Q}(j \omega)^{-n},
$$

where $Q$ is the magnitude of the CPE, $j$ the imaginary unit, $\omega$ the angular frequency and $n$ the CPE exponent.

Table 2 presents the values of electrochemical impedance parameters obtained from the fitting procedure. The EEC used describes the behaviour of a process characterized by two time constants, namely, the high-frequency
(HF) time constant $\left(\mathrm{CPE}_{1}-R_{1}\right)$ and low-frequency (LF) time constant $\left(\mathrm{CPE}_{2}-R_{2}\right)$. Based on the EEC parameter values obtained by fitting the experimental data and also based on the available literature (Omanovic and Roscoe 1999, 2000; Abreu et al 2004), the physical meaning of the HF time constant can be associated with faster charging/discharging and charge-transfer processes, respectively, represented by the double layer/space charge capacitance $\left(\mathrm{CPE}_{1}\right)$ and charge transfer resistance $\left(R_{1}\right)$ parallel combination. On the contrary, the LF time constant $\left(\mathrm{CPE}_{2}-R_{2}\right)$ can be related to slower mass-transport processes in the oxide phase, namely, diffusion of electroactive species (metal ions or oxygen-containing species, i.e. oxygen and metal vacancies, respectively) through the formed passive film. Therefore, the HF time constant can be associated with the properties of the electrode/ electrolyte interface, while the LF time constant reflects the mass-transport processes through the formed passive oxide film. The CPE is a combination of properties related to both the surface and the electroactive species, and is independent of frequency. The results of the fitting procedure indicate that impedance measurements can detect the duplex nature of the oxide layer formed on these types of steels, composed of an inner chromiumrich film which behaves as a $p$-type semiconductor and an outer iron-rich film which behaves as an $n$-type semiconductor (Azumi et al 1986; Ge et al 2001; Sudesh et al 2008; Ha et al 2009). The values of impedance for HNS were higher than that of 316L, and increased with nitrogen content; meanwhile, the phase angle shifted towards higher values. $R_{\mathrm{s}}$ is the resistance of the electrolyte between the working and the reference electrodes, which was obtained almost same for all the tested samples. Taking into account the physical meaning of the EEC, the sum of the two resistances $\left(R_{1}\right.$ and $\left.R_{2}\right)$ is related to the total resistance of surface to general corrosion, which is higher for HNS, indicating the formation of a more 
Table 2. Results of the parameters obtained from the fitting of the equivalent electric circuit to the experimental impedance data obtained for different stainless steels in Hank's solution at $37^{\circ} \mathrm{C}$.

\begin{tabular}{|c|c|c|c|c|c|c|c|c|}
\hline $\begin{array}{l}\text { Stainless } \\
\text { steels }\end{array}$ & $\begin{array}{c}R_{\mathrm{s}} \\
\left(\Omega \mathrm{cm}^{2}\right)\end{array}$ & $\begin{array}{c}\mathrm{CPE}_{1} \\
\left(\mathrm{~F} / \mathrm{cm}^{2}\right)\end{array}$ & $n_{1}$ & $\begin{array}{c}R_{1} \\
\left(\Omega \mathrm{cm}^{2}\right)\end{array}$ & $\begin{array}{c}\mathrm{CPE}_{2} \\
\left(\mathrm{~F} / \mathrm{cm}^{2}\right)\end{array}$ & $n_{2}$ & $\begin{array}{c}\mathrm{CPE}_{2} \\
R_{2}\left(\Omega \mathrm{cm}^{2}\right)\end{array}$ & $\begin{array}{c}R_{\mathrm{ct}} \\
\left(10^{5} \Omega \mathrm{cm}^{2}\right)\end{array}$ \\
\hline 316L & $3 \cdot 21$ & $2.91 \times 10^{-6}$ & $0 \cdot 86$ & $105 \cdot 3$ & $2.64 \times 10^{-5}$ & $0 \cdot 80$ & $3 \cdot 34 \times 10^{4}$ & $0 \cdot 15$ \\
\hline 316LVM & $3 \cdot 74$ & $3.60 \times 10^{-6}$ & $0 \cdot 98$ & $108 \cdot 2$ & $3.25 \times 10^{-5}$ & $0 \cdot 74$ & $3.63 \times 10^{4}$ & $0 \cdot 30$ \\
\hline $316 \mathrm{MnN}_{1}$ & $2 \cdot 29$ & $1.46 \times 10^{-5}$ & 0.67 & $372 \cdot 2$ & $3.43 \times 10^{-4}$ & $0 \cdot 80$ & $4.12 \times 10^{5}$ & 0.65 \\
\hline $316 \mathrm{MnN}_{2}$ & $2 \cdot 79$ & $4.5 \times 10^{-5}$ & $0 \cdot 83$ & $533 \cdot 3$ & $4.38 \times 10^{-4}$ & $0 \cdot 81$ & $5 \cdot 20 \times 10^{5}$ & 1.73 \\
\hline $316 \mathrm{MnN}_{3}$ & $3 \cdot 36$ & $7 \cdot 71 \times 10^{-5}$ & 0.98 & $685 \cdot 5$ & $5.27 \times 10^{-4}$ & 0.94 & $8.42 \times 10^{5}$ & $2 \cdot 20$ \\
\hline
\end{tabular}

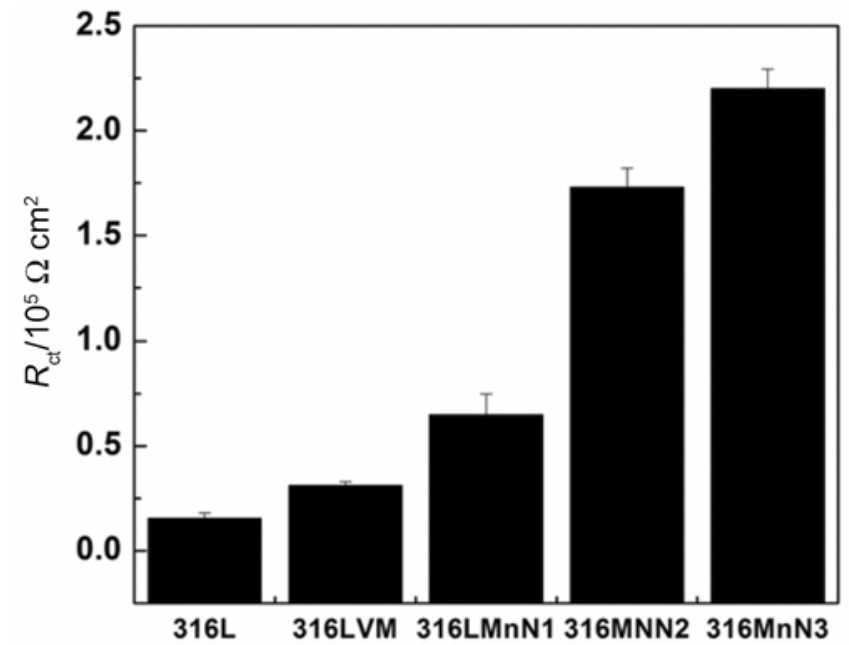

Figure 3. Values of $R_{\mathrm{ct}}$ of different SSs in Hank's solution.

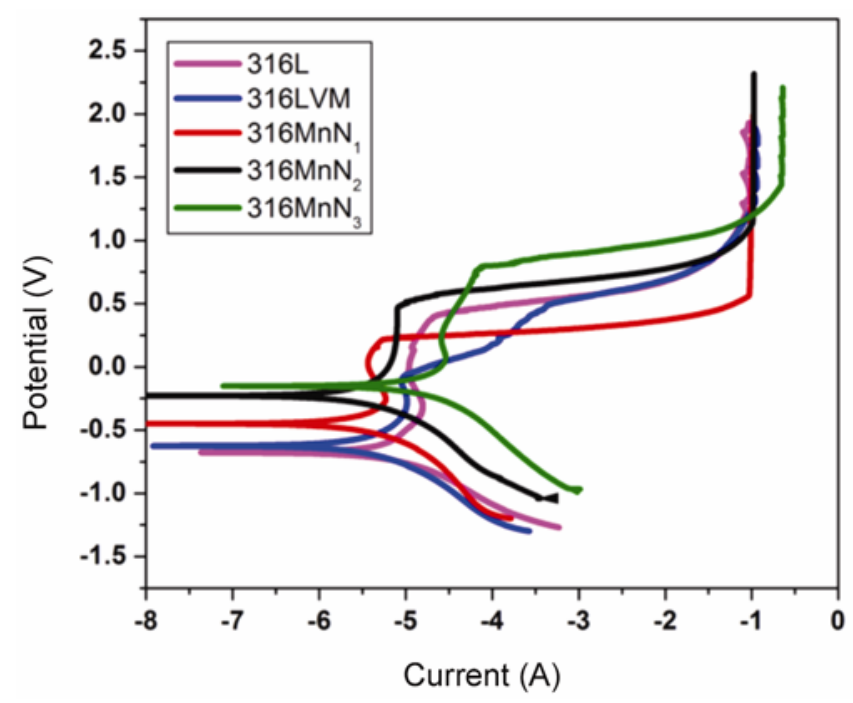

Figure 4. Polarization curves for different SSs in Hank's solution at $37^{\circ} \mathrm{C}$.

protective oxide layer on the surface. The charge transfer resistance $\left(R_{\mathrm{ct}}\right)$ is related to the rate of corrosion reactions at the passive potential. As illustrated in figure 3 , the $R_{\mathrm{ct}}$ increases with increase of nitrogen content in the SS. It was observed that the corrosion resistance of HNS is high, even in the presence of carbon indicating that carbon might not have an effect on the protective layers on the surface of HNS. Meanwhile, some authors observed that the exchange of electrons from blood proteins to the electrode surface of a medical device could induce blood coagulation (Shih et al 2003). The addition of nitrogen improved the $R_{\mathrm{ct}}$ of $\mathrm{SS}$, which would restrain the occurrence of electrons exchange and inhibit the possibility of thrombosis formation.

3.1b Potentiostatic polarization study: Figure 4 shows the polarization curves of different SSs at $37^{\circ} \mathrm{C}$ in Hank's solution. The figure shows that the polarization current is significantly low before the pitting occurs and then the current increases to a high level. Relevant polarization parameters were determined from the tafel extrapolation of polarization curve for the different steels and their values are recorded in table 3. Maximum corrosion rate was observed for the 316L and it decreases with increase in nitrogen content. In essence, the SS with highest nitrogen exhibits the minimum corrosion rate. It has been observed that the values of $I_{\text {corr }}$ for SS samples decreased with increase in nitrogen content and is highest for $316 \mathrm{~L}$. The $E_{\text {corr }}$ for HNSs is more positive and it increases with increase in nitrogen content, indicating that HNS are more corrosion resistant than $316 \mathrm{~L}$ and 316LVM in Hank's solution. These results are in close agreement to the results obtained by EIS studies.

Another important requirement for selecting any material for biomedical application is to determine the breakdown potential $\left(E_{\mathrm{bd}}\right)$, i.e. potential at which the passive film breaks and anodic current strongly increases. In fact, in the presence of chloride ions, the passive layer becomes unstable at this potential and it produces a localized rapid attack of the metal with the formation of pitting. In this study, the maximum breakdown potential is observed for $316 \mathrm{MnN}_{3}$, and decreases with decrease in nitrogen content. But the minimum breakdown potential was observed for $316 \mathrm{MnN}_{1}$ and it is lower than that of 316L; however, its $I_{\text {corr }}$ value is low and $E_{\text {corr }}$ value is more positive. This indicates that the passive film on the surface of carbon-containing SS is unstable at the particular applied potential. This behaviour is different from the obtained results of EIS. 
Table 3. Polarization parameters for different stainless steels in Hank's solution at $37^{\circ} \mathrm{C}$.

\begin{tabular}{|c|c|c|c|c|c|c|}
\hline Stainless steels & $\begin{array}{c}E_{\text {corr }} \\
(\mathrm{V} \text { vs SCE) }\end{array}$ & $\begin{array}{c}I_{\text {corr }} \\
\left(\mu \mathrm{A} \mathrm{cm}^{-2}\right)\end{array}$ & $\begin{array}{c}\beta_{\mathrm{c}} \\
\left(\mathrm{V} \mathrm{\textrm {dec } ^ { - 1 }}\right)\end{array}$ & $\begin{array}{c}\beta_{\mathrm{a}} \\
\left(\mathrm{V} \mathrm{dec}{ }^{-1}\right)\end{array}$ & $\begin{array}{l}\text { Corrosion are } \\
\left({\left.\text { mils } y^{-1}\right)}^{-1}\right.\end{array}$ & $\begin{array}{c}E_{\mathrm{bd}} \\
\text { (V vs SCE) }\end{array}$ \\
\hline 316L & $-0 \cdot 655$ & $5 \cdot 556$ & $5 \cdot 546$ & $3 \cdot 202$ & $2 \cdot 359$ & 0.403 \\
\hline 316LVM & $-0 \cdot 585$ & $5 \cdot 169$ & $5 \cdot 655$ & $3 \cdot 461$ & $2 \cdot 247$ & $0 \cdot 489$ \\
\hline $316 \mathrm{MnN}_{1}$ & $-0 \cdot 369$ & 3.668 & $4 \cdot 979$ & $4 \cdot 045$ & $1 \cdot 667$ & $0 \cdot 194$ \\
\hline $316 \mathrm{MnN}_{2}$ & $-0 \cdot 309$ & $2 \cdot 906$ & $5 \cdot 198$ & $4 \cdot 288$ & $1 \cdot 321$ & $0 \cdot 437$ \\
\hline $316 \mathrm{MnN}_{3}$ & $-0 \cdot 236$ & $2 \cdot 663$ & $5 \cdot 597$ & $4 \cdot 559$ & $1 \cdot 210$ & $0 \cdot 523$ \\
\hline
\end{tabular}

In comparison with 316L, the HNS showed evidently much lower passive current density, suggesting that the passive film formed on the HNS is more protective. In general, during the pit propagation, the local environment is acidified by the hydrolysis of the dissolving metal, and the metal inside the pit is maintained in an actively dissolving state according to

$$
\mathrm{Me}^{z+}+\mathrm{H}_{2} \mathrm{O} \rightarrow \mathrm{MeOH}^{(z-1)}+\mathrm{H}^{+} .
$$

It is believed that nitrogen in the steel dissolves; it consumes protons in the pit to form ammonia, thus, preventing a lowering of the $\mathrm{pH}$ in the pit, which contributes to the suppression of acidification inside the pit (Osozawa et al 1975; Osozawa and Okato 1976; Palit et al 1993). It is also speculated that surface films are stabilized through passivation or nitrogen enrichment of the film/metal interface to prevent the attack of chloride ions ( $\mathrm{Lu}$ et al 1983; Vanini et al 1994; Olsson 1995). The increase of nitrogen content enhanced the corrosion resistance of SS, thus, improving the biocompatibility. It has also been observed from the results that the $316 \mathrm{LVM}$ is more corrosion resistant than 316L. Similar results were obtained in our previous study (Talha et al 2012). There are many other factors that affect the corrosion behaviour of steels such as impurities, microstructure, electrolytes, $\mathrm{pH}$ values and so on. It is well known that some inclusions on the surface of stainless steels accelerate pitting. $316 \mathrm{LVM}$ is a vacuum-melted alloy ( $\mathrm{VM}=$ vacuum melted), so it has less inclusions compared to 316L. Hence, the impurity elements such as $\mathrm{S}, \mathrm{P}$ and oxides in 316LVM steels is lower, and then the nucleation sites for pitting, such as MnS inclusions, were probably reduced (Yu 1987; Shahryari et al 2008), which decreased the susceptibility to pitting attacks.

3.1c Scanning electron microscopy (SEM) analysis: At the end of the polarization tests, surfaces of all samples were observed by SEM in order to analyse the pitting corrosion on surface of SSs. Figure 5(a-e) shows the SEM micrograph of the different SS surfaces after the polarization test in Hank's solution. SEM micrographs confirm the pitting corrosion on the surface of SSs. Pits were in fact found on all the steel sample surfaces, but few pits were observed for the steel having highest nitrogen. However, the surface of the 316L and 316LVM corroded much more in Hank's solution, which reveals the presence of many open perforated pits and pits were deeper and bigger than those on nitrogen-bearing steels. It is very interesting to note that the samples which have higher carbon content also have very less number of pits indicating that nitrogen suppresses the pit formation, even in presence of carbon. This indicates that the nitrogen-bearing alloy is suitable for biomedical applications.

\subsection{Contact angle}

The values of contact angle obtained with distilled water are shown in table 4. It can be seen that all the differences are statistically significant for the experimental materials, among which the HNS is more hydrophilic than 316L and 316LVM. Increasing nitrogen content enhances the hydrophilic character, i.e. lower contact angle (CA) values.

\subsection{Cytocompatibility evaluation}

Figure 6 represents the results of cell proliferation on various surfaces of SS samples after 48 and $72 \mathrm{~h}$, determined by the MTT test. Results indicate that the cell proliferation increases significantly $(P \leq 0.05-0.001)$ in a time-dependent manner for all the prepared samples. All the samples permitted cell proliferation and no sample exerts any cytotoxic effect on cell proliferation/viability. The significant difference in cell proliferation between 316L and HNS is observed and it is higher for HNS than that of 316L and 316LVM, and increases with increasing nitrogen content. The results demonstrate that all samples do not cause any reduction or inhibition in cell viability or proliferation. Interestingly, cell proliferation/viability was detected higher in carbon-containing sample than in $316 \mathrm{~L}, 316 \mathrm{LVM}$ and even than in $316 \mathrm{MnN}_{2}$, indicating that the carbon does not exert any negative effect on cell proliferation and enhances the proliferation/viability of cells. The difference between the numbers of proliferating DL cells on the surface of different SS coupons for 1 , 3 and 5 days was examined, which indicate that adhesion of cells increases in a time-dependent manner and has been observed significantly higher on fifth day of cells incubation as compared to cells incubated for one and three days as shown in figure 7. Significant increase in the number of cells with time on all the sample 

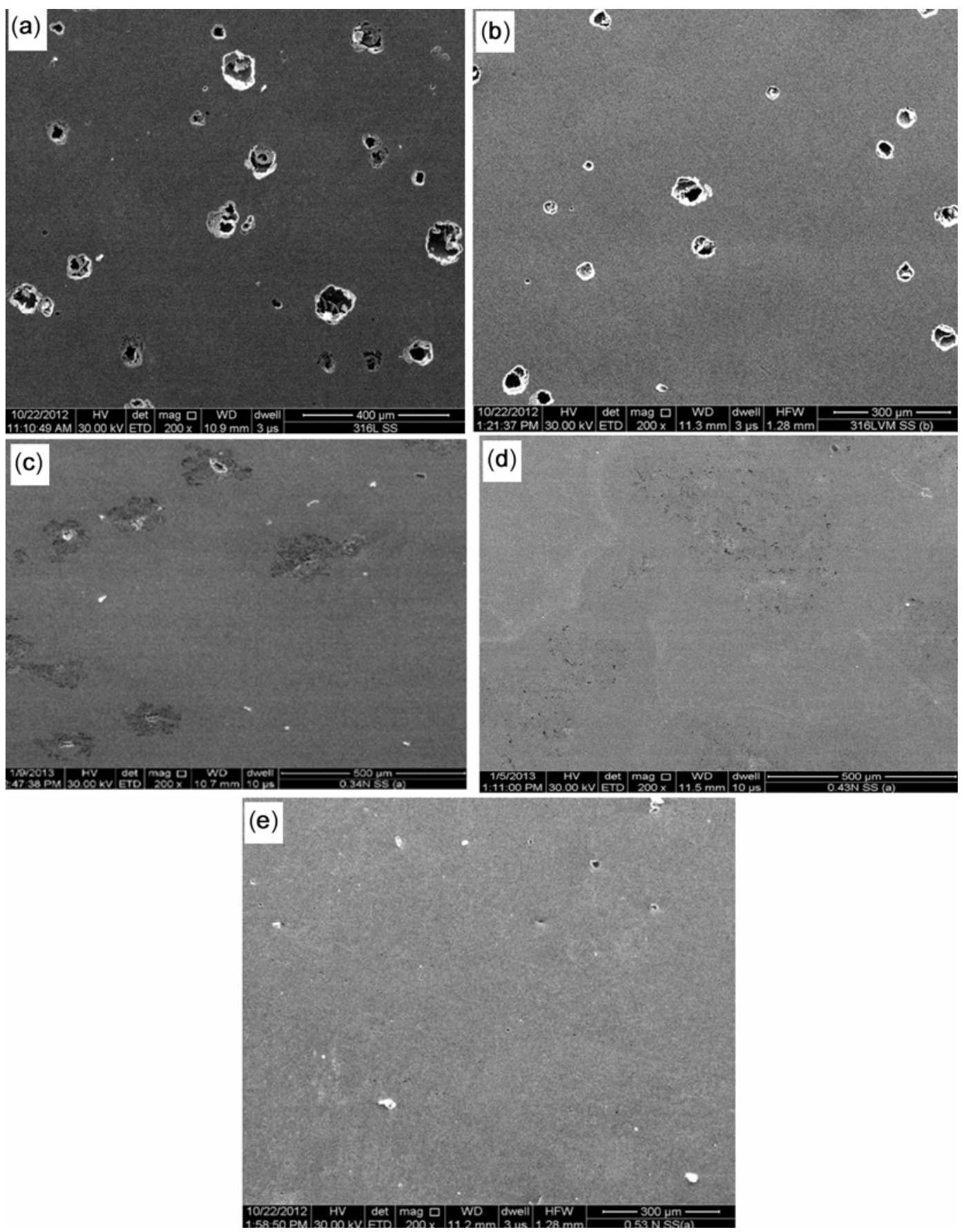

Figure 5. SEM micrographs of (a) $316 \mathrm{~L}$, (b) $316 \mathrm{LVM}$, (c) $316 \mathrm{LMnN}_{1}$, (d) $316 \mathrm{MnN}_{2}$ and (e) $316 \mathrm{MnN}_{3}$ after polarization test in Hank's solution.

Table 4. Contact angle values (degree) obtained with distilled water on the surface of different SSs.

\begin{tabular}{lcccc}
\hline $316 \mathrm{~L}$ & $316 \mathrm{LVM}$ & $316 \mathrm{MnN}_{1}$ & $316 \mathrm{MnN}_{2}$ & $316 \mathrm{MnN}_{3}$ \\
\hline 79.68 & 77.41 & 67.14 & 69.18 & 64.19 \\
\hline
\end{tabular}

surfaces suggest that all samples do not exert any growth inhibitory effect on DL cells proliferation. The number of adherent cells population was observed higher on HNS than on 316L and 316LVM. This was confirmed by count- ing the number of cells in six random areas of $0.03 \mathrm{~cm}^{2}$ in the SEM images of the different samples and determining the average (figure 8). Therefore, results obtained from the present studies suggest that the number of adherent cells population at different coupons of SS-containing nitrogen was higher due to the high rate of cells proliferation, which was confirmed by SEM results. There was no evidence of changes in cell morphology or damage. The corrosion resistance of SSs is enhanced with nitrogen content, which represented a reduction of corrosion 
products available to interact with the biological environment. Therefore, HNS could exhibit better cytocompatibility with increasing nitrogen content, in comparison to $316 \mathrm{~L}$ and $316 \mathrm{LVM}$.

It has been observed that HNS with different nitrogen content has an influence on the surface energy value, which in turn influenced the cytocompatibility. With increasing nitrogen content, the surface wettability and total surface free energy (SFE) increase (Ma et al 2012). The increase in SFE is due to increase in polar component $\left(\gamma_{s}^{p}\right)$, which increases with nitrogen content in the alloy. High polar components improve the wettability of material (Wan et al 2010). Oxide layer with high surface energy on the surface of biomaterials is hydrophilic because of binding structural water and formation $-\mathrm{OH}$ and $-\mathrm{O}^{2-}$ groups in its outermost layer (Zhao et al 2007). In general, the biomaterial with high surface energy is conducive to cell adhesion and spreading. Surface energy modulates protein adsorption, which further regulates cell adhesion, cell spreading and proliferation (Kennedy et al 2006). This can have consequences for the in vivo response to a material. Higher surface energy and increased wettability have been shown to enhance interaction between an implant surface and its biological environment (Baier et al 1984). It is clear from contact angle measurements that nitrogen in steel influences the hydrophilic character of steel and it increases with nitrogen content, which in turn influences the cytocompatibility. Thus, it is deduced that HNS exhibits better cell adhesion and cytocompatibility with increasing nitrogen content. Further, the samples containing carbon and nitrogen show more cell proliferation and cell adhesion, indicating that carbon has no adverse effect and somewhat also enhances the cell proliferation. These results

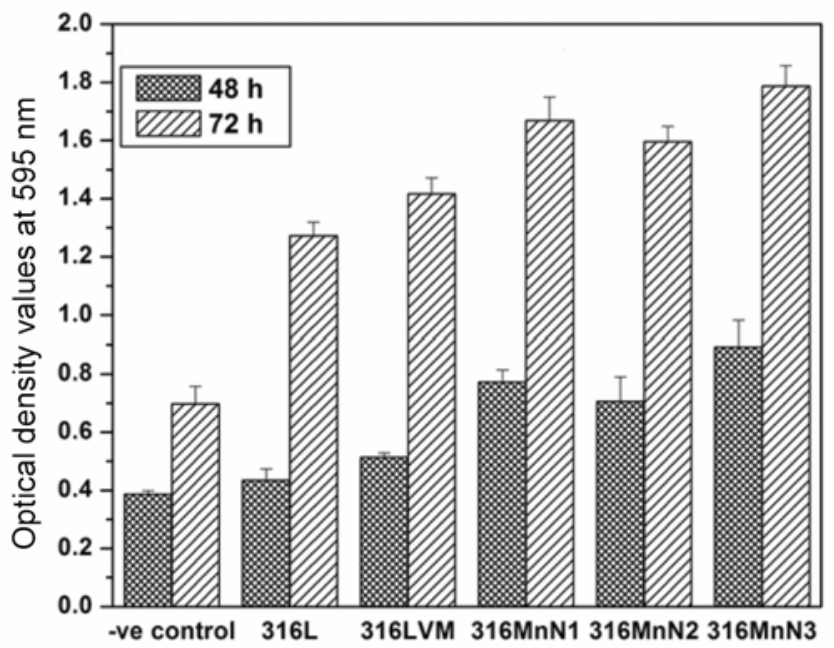

Figure 6. OD values of DL cells on different SSs determined by MTT assay after 48- and 72-h incubation.
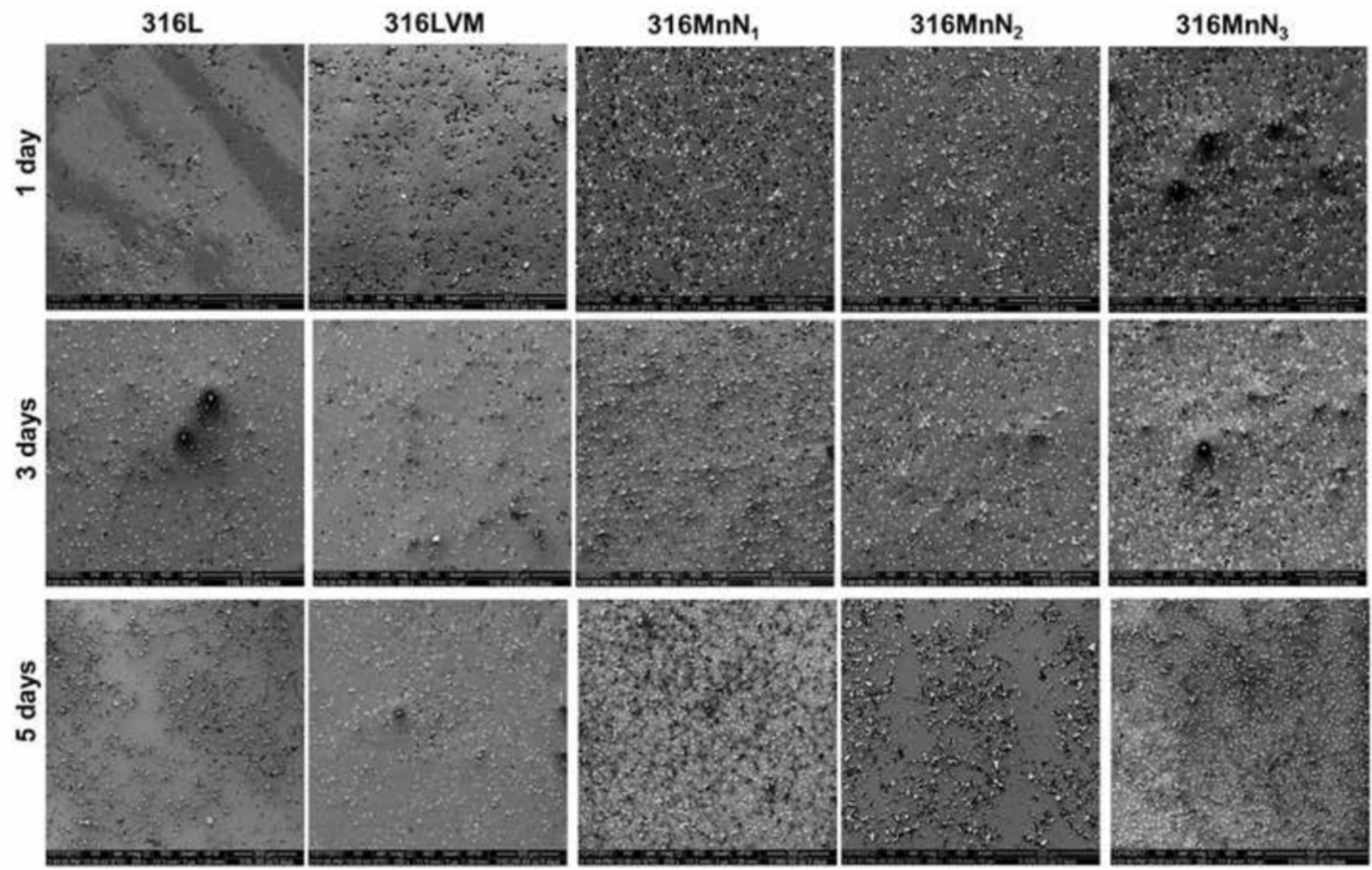

Figure 7. SEM images of DL cells cultured on different SS surfaces after 1,3 and 5 days incubation. 


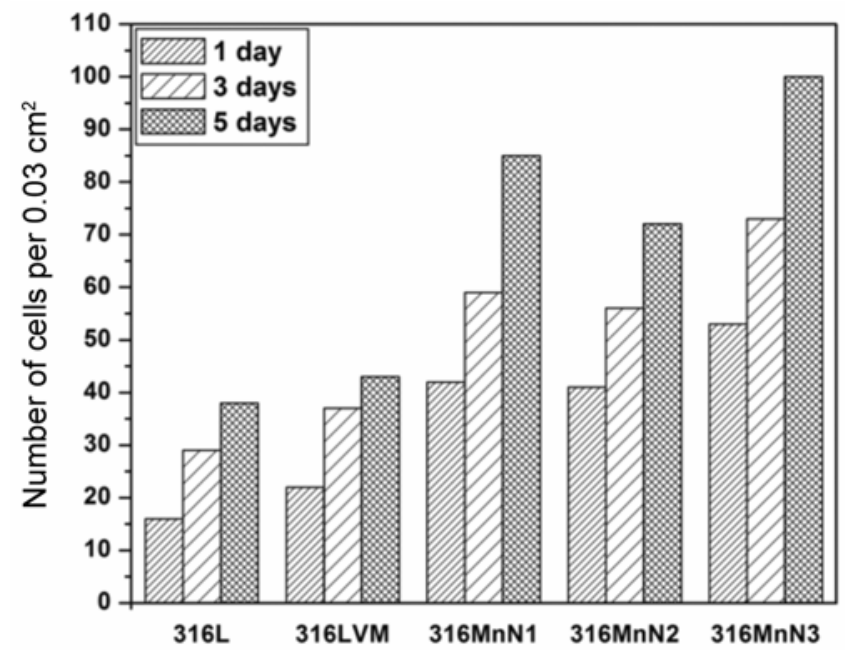

Figure 8. Average number of cells counted in six random areas of $0.03 \mathrm{~cm}^{2}$ of each SS sample.

are in close agreement with those obtained by Buhagiar et al (2011). They studied S-phase surface layers formed on 316LVM and HNS by plasma surface alloying with nitrogen, carbon and both carbon and nitrogen and reported that osteoblast cells prefer surfaces that are rich in both nitrogen and carbon.

\section{Conclusions}

The results indicated the formation of a more protective oxide layer on the surface of HNS which was demonstrated by the higher values of $R_{1}$ and $R_{2}$. HNS exhibited higher value of $R_{\mathrm{ct}}$. The EIS spectra are best fitted using an electrical equivalent circuit (EEC) characterized by two branches (CPE, $R$ in parallel). This EEC is consistent with the model of a two-layer structure for the passive film. The values of the $I_{\text {corr }}$ for SS samples decreased with increase in nitrogen content. The $E_{\text {corr }}$ for nitrogen bearing SS are more positive. The maximum corrosion rate was observed for the 316L and it decreases with increase in nitrogen content. The maximum breakdown potential was observed for $316 \mathrm{MnN}_{3}$, and the minimum breakdown potential was observed for $316 \mathrm{MnN}_{1}$. It has also been observed from the results that the $316 \mathrm{LVM}$ is more corrosion resistant than 316L. As to the pits, morphology, shallower and smaller pits were associated with HNS compared with 316L and 316LVM. The steel having more carbon content show less number of pits, indicating that nitrogen suppresses the pit formation even in the presence of carbon. The HNS had higher cell proliferation and cell growth and it increases by increasing nitrogen content. The value of contact angles was found to decrease with increase in nitrogen content. This indicates that the hydrophilic character increases with increase in nitrogen content, which is further attributed to enhance the surface free energy, which would be conducive to cell adhesion, which in turn increases the cell proliferation. Therefore, HNS could show better corrosion resistance and biocompatibility due to the reduction of metallic ions and corrosion products available to interact with the biological environment. However, further studies are essential for these materials before using it for biomedical applications.

\section{Acknowledgements}

Authors are thankful to Prof Gurmeet Singh, Department of Chemistry, University of Delhi, Delhi, India, for providing facility of electrochemical tests in his laboratory. One of the authors, Mohd Talha, is pleased to acknowledge the financial support as Senior Research Fellowship provided by the University Grants Commission (UGC), New Delhi, India.

\section{References}

ASTM F 2581-07, Standard specification for wrought nitrogen strengthened 11 manganese-17 chromium-3 molybdenum low-nickel stainless steel alloy bar and wire for surgical implants (UNS S29225)

Azumi K, Ohtsuka T and Sato N 1986 Trans. Jpn. Inst. Met. 27 382

Abreu C M, Cristobal M J, Losada R, Novoa X R, Pena G and Perez M C 2004 J. Electroanal. Chem. 572335

Baier R E, Meyer A E, Natiella J R, Natiella R R and Carter J M 1984 J. Biomed. Mater. Res. 18327

Bal W, Kozoowski H and Kasprzak K 2000 J. Inorg. Biochem. 79213

Baba H, Kodama T and Katada Y 2002 Corros. Sci. 442393

Buhagiar J, Bell T, Sammons R and Dong H 2011 J. Mater. Sci: Mater. Med. 221269

Clayton C R 1986 Passivity mechanisms in stainless steels: Mo-N synergism, Report No. N00014-85-K-0437. New York

Disegi J A and Eschbach L 2000 Injury 314

Fini M, Aldini N, Torricelli P, Glavaresi G, Borsari V, Lenger H, Bernauer J, Glardino R, Chiesa R and Cigada A 2003 Biomaterials 244929

Fini M et al 2004 J. Biomed. Mater. Res. B Appl. Biomater. B71 30

Gurappa I and Kumar M K 2000 Evaluation of corrosion resistance of plasma sprayed alumina, magnesia-stabilized zirconia and yttrium-stabilized zirconia coatings on 316 stainless steel for biomedical applications. Proceedings of Global 2000 Corrosion Meeting (Mumbai, India: Quest Publications), vol 1, p 561

Ge H, Zhou G and Wu W 2001 Appl. Surf. Sci. 211321

Gurappa I 2002 Mater. Charac. 4973

Ha H Y, Jang H, Kwon H S and Kim S J 2009 Corros. Sci. $\mathbf{5 1} 48$

IARC 1999 Monographs on the evaluation of carcinogenic risks to humans: surgical implants and other foreign bodies (Lyon) vol. 74, p 65 
Jorcin J B, Orazem M E, Pebere N and Tribollet B 2006 Electrochim. Acta 511473

Kuroda D, Hiromoto S, Hanawa T and Katada Y 2002 Mater. Trans. 433100

Kennedy S B, Washburn N R, Simon Jr C G and Amis E J 2006 Biomaterials 273817

Lu Y C, Bandy R, Clayton C R and Newman R C 1983 J. Electrochem. Soc. 1301774

Lee J B 2006 Mater. Chem. Phys. 99224

Mudali U K, Reynders B and Stratmann M 1994 Mat. Sci. Forum.723 185

Menzel J, Kirschner W and Stein G 1996 ISIJ Int. 36893

Mudali U K, Dayal R K, Gnanamoorthy J B and Rodriguez P 1996 Mat. Trans. JIM 371568

Milosev I and Strehblow H H 2000 J. Biomed. Mater. Res. 52404

Ma T, Wan P, Cui Y, Zhang G, Li J, Liu J, Ren Y, Yang K and Lu L 2012 J. Mater. Sci. Technol. 28647

Newman R C, Lu Y C, Bandy R and Clayton C R 1984 Proceedings of the ninth International congress on metallic corrosion (Ottawa, Canada: National Research Council), vol 4, p 394

Newman R C and Shahrabi T 1987 Corros. Sci. 27827

Osozawa K, Okato N, Fukase Y, Yokota K and BoshokuGijyutsu 1975 Corros. Eng. 241

Osozawa K, Okato N, Stahele R W and Okada H (eds) 1976 in Passivity and its breakdown on iron and iron base alloys (NACE), p 135

Olsson C O A 1995 Corros. Sci. 37467

Ohno H, Tanabe H, Sakai A, Misawa T and Zairyo-to-Kankyo 1998 Corros. Eng. 47584

Omanovic S and Roscoe S G 1999 Langmuir 158315

Omanovic S and Roscoe S G 2000 J. Coll. Interf. Sci. 227452

Olsson C O A and Landolt D 2003 Electrochimica Acta 481093
Palit G C, Kain V and Gadiyar H S 1993 Corrosion 49977

Pattersson R F A J 1999 Corros. Sci. 411639

Ren Y, Wan P, Liu F, Zhang B and Yang K 2011 J. Mater. Sci. Technol. 27325

Sumita M 1997 Orthop. Surg. 48927

Schmidt C, Ignatius A and Claes L E 2001 J. Biomed. Mater. Res. 54209

Shih C C, Shih C M, Su Y Y and Lin S J 2003 J. Biomed. Mater. Res.: Part A $\mathbf{6 7} 1320$

Shahryari A, Omanovic S and Szpunar J A 2008 Mater. Sci. Eng. C28 94

Sudesh T L, Wijesinghe L and Blackwood D J 2008 Corros. Sci. $\mathbf{5 0} 23$

Tschiptschin A, Aidar C, Neto F and Alonso-Falleiros N 1999 Mater. Sci. Forum $\mathbf{5 6 9} 318$

Thomann U I and Uggowitzer P J 2000 Wear 23948

Takazawa K, Miyagawa H and Hariya A 2003 Jpn. Soc. Artif. Organs. 671

Talha M, Behera C K and Sinha O P 2012 J. Chem. Pharmaceut. Res. 4203

Vanini A S, Audouard J P and Marcus P 1994 Corros. Sci. 361825

Vahter M, Berglund M, Akesson A and Liden C 2002 Environ. Res. 88145

Woodman J L, Jacobs J J, Galante, J O and Urban R M 1984 J. Orthop. Res. 1421

Wan P, Ren Y, Zhang B and Yang K 2010 Mater. Sci. Eng. C30 1183

Yu Z S 1987 Applications of rare earths in iron and steel (in Chinese), (Beijing: Metallurgical Industry Press) p 282

Yamamoto A, Kohyama Y, Kuroda D and Hanawa T 2004 Mater. Sci. Eng. C24 737

Zhao G, Raines A L, Wieland M, Schwartz Z and Boyan B D 2007 Biomaterials 282821 